\title{
Experimental study on heat transfer of concrete at high temperatures under hygrothermal environment
}

\author{
Min $\mathrm{Tu}^{1}$, Jun Deng ${ }^{1 *}$, and $Y i$ Wang $^{2}$ \\ School of Civil and Transportation Engineering, Guangdong University of Technology ,510006 Guangzhou, China
}

\begin{abstract}
Safety of concrete structures could be threatened under fire exposure, especially for structures under hygrothermal environment. Existing studies have shown that concrete contains large amount of moisture could induce spalling failure and the temperature is a critical parameter for the damage. However, until now, the study for heat transfer of concrete with different saturation degree remains limited. In this paper, the temperature increase of concrete specimens with different saturation degree is experimentally studied. Results show that the temperature increase rate could be affected by the moisture content significantly, especially for the cases under higher temperatures. The test results could be significant for our future fire damage simulation of concrete structures under hygrothermal environment.
\end{abstract}

\section{Introduction}

High temperature may induce concrete peeling off or even burst when it subjected to hot and humid environment $^{[1 \sim 5]}$, which can threaten the safety of concrete structures, as well as people's lives and property. Temperature field analysis is the basis for damage assessment of concrete structures under fire. However, for simulation of temperature field in concrete, the influence of moisture is usually neglected, which may result in inaccurate evaluation. Although many researchers concerned the influence of water content on the mechanical properties of concrete members under high temperature ${ }^{[6 \sim 11]}$, the results remain limited and it is rather difficult to carry out accurate numerical simulation. In addition, the European specification ${ }^{[12]}$ provided the correction value of concrete specific heat during the period from $100{ }^{\circ} \mathrm{C}$ to $200{ }^{\circ} \mathrm{C}$, which can be used to correct the temperature field of concrete under high temperature. But the correction value is empirical and the relationship between the correction value and the moisture content is not clear. It requires further investigation on the influence of moisture effect on the temperature field.

Thus, in order to accurately simulate the temperature distribution of concrete under hot and humid environment, and to clarify the influence of moisture on the temperature conduction of concrete under high temperature, the internal heating transfer of concrete specimens with different saturations at high temperature was studied in this paper. The results could be beneficial to fast and effective evaluation of fire-damaged concrete structures under hygrothermal environment.

\section{Test Programme}

The experiment programme can be divided into two steps. Firstly, the average water content of saturated concrete specimens were measured by drying. In total, 15 concrete specimens were prepared and tested. The specimens were placed in an oven at 105 degree until the weight become constant. In this case, it is believed that the concrete is completely dried. The mass loss of concrete due to drying was obtained, which is the water content. Then, concrete specimens were immersed in water tank for different period to obtain different water saturation. After that, they were placed in the same heating environment and the heat transfer information at the same positions were measured.

\subsection{Materials and specimens}

In this test, a total of 19 concrete specimens were prepared, which have the dimensions of $100 \times 100 \times$ $100 \mathrm{~mm}$. Ordinary Portland cement with a strength of 42.5 $\mathrm{MPa}$ was used. Gravels with particle sizes of $5-20 \mathrm{~mm}$ were applied as the coarse aggregate. The fine aggregate was ordinary river sand and the maximum diameter is $5 \mathrm{~mm}$. The moisture content of the sand was $0.01 \%$, while the water content of the gravels was $0.008 \%$. The mixture of concrete material is shown in Table 1. During casting, the specimens were mechanical stirring, manual pouring and mechanical vibration. The stirring rate was $45 \pm 2 \mathrm{r} / \mathrm{min}$ and the vibration time was 2 min. The environmental humidity during pouring was $75 \% \sim 85 \%$. After the specimen was cased for one day, the mold was removed. Then the specimens were standard cured for 28 days.

$\overline{\text { Corresponding author:jdeng@gdut.edu.cn }}$ 
Table.1 Concrete mix ratio

\begin{tabular}{|c|c|c|c|c|c|}
\hline $\begin{array}{c}\text { Water } \\
\text { cement } \\
\text { ratio }\end{array}$ & $\begin{array}{c}\text { Cement } \\
\mathbf{~ k g} / \mathbf{m}^{\mathbf{3}}\end{array}$ & $\begin{array}{c}\text { Water } \\
\mathbf{k g} / \mathbf{m}^{\mathbf{3}}\end{array}$ & $\begin{array}{c}\text { Sand } \\
\mathbf{k g} / \mathbf{m}^{\mathbf{3}}\end{array}$ & $\begin{array}{c}\text { Stone } \\
\mathbf{~ k g} / \mathbf{m}^{\mathbf{3}}\end{array}$ & $\begin{array}{c}\text { Sand } \\
\text { rate } \\
\mathbf{\%}\end{array}$ \\
\hline 0.5 & 410 & 205 & 611 & 1134 & 35 \\
\hline
\end{tabular}

\subsection{Estimation of water content in concrete}

Concrete specimens were placed in an oven and dried continuously under the temperature of $105{ }^{\circ} \mathrm{C}$. During drying, the mass of specimens were measured continuously, as shown in Fig.1.. The moisture content value was shown in Table 2. As can be seen from Fig. 1, the time-dependent mass change and the change rate of the concrete were similar for each specimen. The rate of change was the fast in the first 1 10 days and the mass of concrete become almost constant at around 30 days. Then the concrete was taken out. As observed in Table 2, the water mass of the concrete can be calculated and the values were mainly within $0.40 \sim 0.50 \mathrm{~g}$. Therefore, the average moisture ratio of the saturated concrete can be estimated. The average water content was $5.08 \%$ and the results are shown in Table 2 . Based on the average moisture content, the saturation degree of the reabsorbed specimens can be estimated, as shown in Table 3.

Table. 2 Concrete water loss results

\begin{tabular}{|c|c|c|c|c|}
\hline $\begin{array}{c}\text { Specim } \\
\text { en } \\
\text { No. }\end{array}$ & $\begin{array}{c}\text { Original } \\
\text { mass } \\
\mathbf{g}\end{array}$ & $\begin{array}{c}\text { The } \\
\text { mass } \\
\text { after } \\
\text { drying } \\
\text { g }\end{array}$ & $\begin{array}{c}\text { Water } \\
\text { content } \\
\mathrm{g}\end{array}$ & $\begin{array}{c}\text { Average } \\
\text { moisture } \\
\text { content } \\
\%\end{array}$ \\
\hline W-1 & 9.64 & 9.12 & 0.52 & \multirow{15}{*}{5.08} \\
\hline W-2 & 9.56 & 9.02 & 0.54 & \\
\hline W-3 & 9.76 & 9.24 & 0.52 & \\
\hline W-4 & 9.76 & 9.22 & 0.54 & \\
\hline W-5 & 9.68 & 9.18 & 0.50 & \\
\hline W-6 & 9.78 & 9.24 & 0.54 & \\
\hline W-7 & 9.80 & 9.24 & 0.56 & \\
\hline W-8 & 9.80 & 9.28 & 0.52 & \\
\hline W-9 & 9.72 & 9.18 & 0.54 & \\
\hline W-10 & 9.54 & 9.12 & 0.42 & \\
\hline W-11 & 9.54 & 9.08 & 0.46 & \\
\hline W-12 & 9.50 & 9.08 & 0.42 & \\
\hline W-13 & 9.32 & 8.94 & 0.38 & \\
\hline W-14 & 9.58 & 9.1 & 0.48 & \\
\hline W-15 & 9.42 & 9.02 & 0.40 & \\
\hline
\end{tabular}

\subsection{Arrangement of measuring points}

The temperatures of the concrete surface and inside were measured by a 16-channel temperature collector with an accuracy of $\pm 2{ }^{\circ} \mathrm{C}$. It can measure at the set time, display and export the temperature value corresponding to each measuring point and. Then the heating curve can be obtained. After the specimen was prepared, the K-type thermocouple was embedded inside with a depth of $30 \pm$ $2 \mathrm{~mm}$. The measurement range of the device was range from $-50{ }^{\circ} \mathrm{C} \sim 1300{ }^{\circ} \mathrm{C}$. The measuring points were placed at the specimen surface and inside respectively. The detailed layout of the measuring points was shown in Fig. 2.

Table.3 Specimens arrangement for heat transfer test

\begin{tabular}{|c|c|c|c|c|}
\hline $\begin{array}{c}\text { Specimen } \\
\text { No. }\end{array}$ & $\begin{array}{c}\text { Temper } \\
\text { ature } \\
{ }^{\circ} \mathbf{C}\end{array}$ & $\begin{array}{c}\text { Heating } \\
\text { rate }\end{array}$ & $\begin{array}{c}\text { Maximum } \\
\text { temperature } \\
{ }^{\circ} \mathbf{C}\end{array}$ & $\begin{array}{c}\text { Moisture } \\
\text { content } \\
\mathbf{\%}\end{array}$ \\
\hline W-200-1 & 200 & $20 \% / \mathrm{min}$ & 200 & 24.19 \\
\hline W-200-2 & 200 & $20 \% / \mathrm{min}$ & 200 & 100 \\
\hline W-400-1 & 400 & $20 \% / \mathrm{min}$ & 400 & 24.19 \\
\hline W-400-2 & 400 & $20 \% \mathrm{~min}$ & 400 & 100 \\
\hline
\end{tabular}

Note: The method of estimating the saturation is 1 minus the quotient of the mass change rate of the concrete divided by the average moisture content of the concrete of $5.08 \%$.

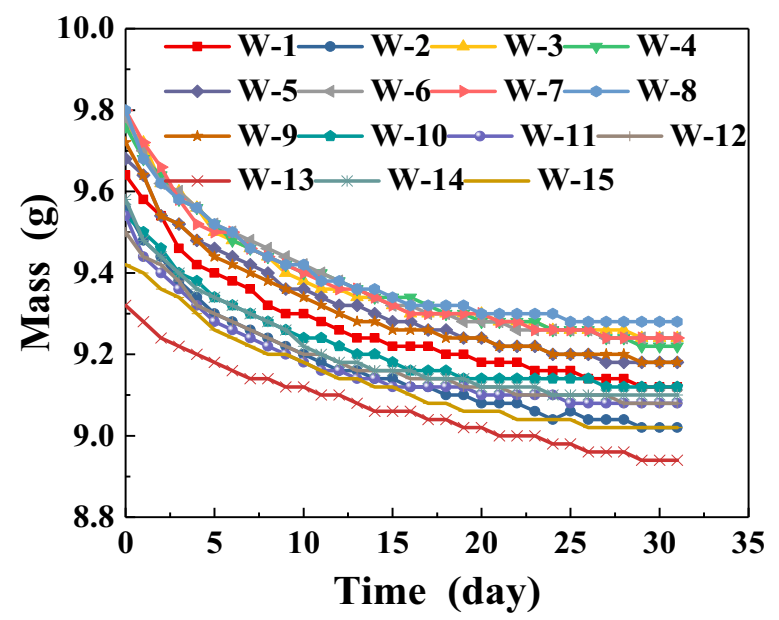

Fig.1 Mass change chart

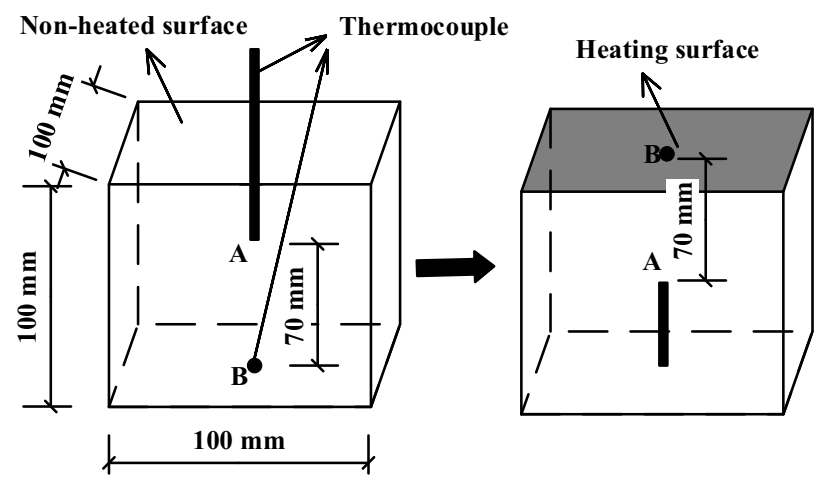

Fig.2 Detail of specimen with thermocouple arrangement

\subsection{Experimental procedure and heating method}

The heating device in this test used the high temperature furnace with TCW-32B system and PID intelligent temperature control technology. The heating element is U-shaped silicon carbon rod. The maximum heating temperature is $800{ }^{\circ} \mathrm{C}$ and the maximum heating rate is $30{ }^{\circ} \mathrm{C} / \mathrm{min}$, in which the temperature is controlled. Using PID intelligent control technology, different heating rate can be set. The surrounding and bottom surfaces of the concrete specimens were insulated with an aluminum 
silicate cushion to simulate one-dimensional heat conduction of concrete specimens. The material heat transfer coefficients of the aluminum silicate underlayer are shown in Table 4. As indicated, the heat insulation properties are good. The temperature inside the furnace was heated to $200^{\circ} \mathrm{C}$ and $400^{\circ} \mathrm{C}$ at a heating rate of $20^{\circ} \mathrm{C} / \mathrm{min}$, respectively. The duration of heating was lasting for about $180 \mathrm{~min}$, and the data was collected during heating.

Table.4 Aluminium silicate cushion heat transfer coefficient table

\begin{tabular}{|c|c|}
\hline $\begin{array}{c}\text { Temperature } \\
{ }^{\circ} \mathbf{C}\end{array}$ & $\begin{array}{c}\text { Material heat transfer } \\
\text { coefficient } \\
\mathbf{m} \cdot \mathbf{k}\end{array}$ \\
\hline 100 & 0.019 \\
\hline 200 & 0.022 \\
\hline 300 & 0.024 \\
\hline 400 & 0.028 \\
\hline 500 & 0.034 \\
\hline 600 & 0.039 \\
\hline
\end{tabular}

\section{Test results and analysis}

Figure 3 shows the time-dependent temperature curves of the $\mathrm{A}$ and $\mathrm{B}$ measuring points of the concrete with different saturation at a heating rate of $20^{\circ} \mathrm{C} / \mathrm{min}$ and a maximum temperature of $200{ }^{\circ} \mathrm{C}$. Due to the poor thermal conductivity of the insulation layer, it is impossible to accurately simulate the unidirectional conduction of concrete at high temperatures, resulting in an excessive internal temperature.The maximum exposure temperature was set by the PID setting of the furnace. At point $\mathrm{P}$, overshoot occurs due to the high temperature control system. As can be seen from Fig. 3, at the same heating rate, the temperature change trend of each measuring point is similar. While the temperature on the surface of concrete increase rapidly, the temperature inside of concrete increase pretty slow regardless of the concrete saturation degree, especially in the initial stage. As the temperature increases, the temperature difference between the heating temperature inside the concrete and the surface gradually decreases $^{[13]}$. As observed, at the initial stage, the temperatures of the two specimens were inconsistent with a difference of about $4{ }^{\circ} \mathrm{C}$. The reason may be attributed to the water content different in the two tested specimens. Since the water content of the sample one is smaller, the internal temperature is higher under the sample exposure temperature compared with sample two. The surface temperature of concrete with different saturations is quite different. There are two explanations for this phenomenon. One is due to the high water content of the concrete. The water evaporated from the surface, which causes the temperature drop on the surface. The second is due to the PID control system of the high temperature box furnace. When the maximum temperature set is $200{ }^{\circ} \mathrm{C}$, the temperature distribution in the furnace may be uneven, which causes the heating difference of concrete at different locations.

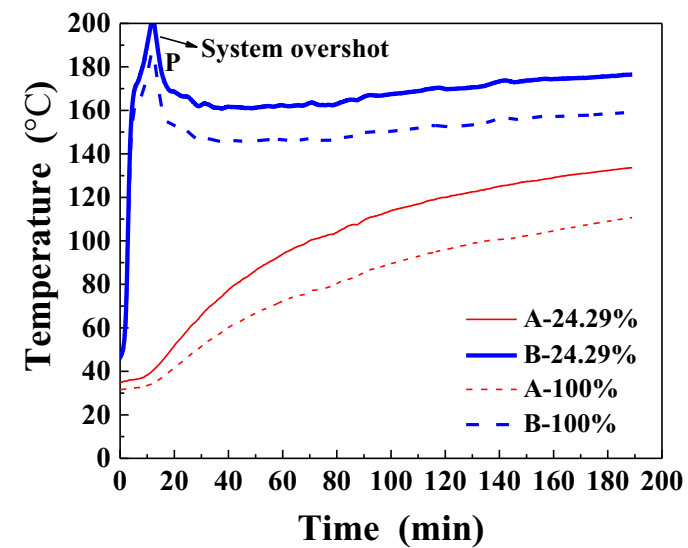

Fig3. Effect of saturation on concrete temperature conduction at $200{ }^{\circ} \mathrm{C}$ high temperature

Figure 4 shows the time-dependent temperature curves of the $\mathrm{A}$ and $\mathrm{B}$ measuring points of the concrete with different saturation at a heating rate of $20{ }^{\circ} \mathrm{C} / \mathrm{min}$ and a maximum temperature of $400{ }^{\circ} \mathrm{C}$. However, it seems the target temperature is difficult to achieve by the device. As observed, point $a$ in the figure is the stagnation point. The sudden drop in temperature at point $a$ is due to the large amount of free water inside. When the temperature reached $100^{\circ} \mathrm{C}$, the water evaporates and absorbs heat. It takes away a large amount of heat, causing the internal temperature decrease. Explain that different saturations have a significant effect on the temperature distribution of concrete at high temperatures. The point $b$ was defined as the failure point, where the temperature rises sharply. The reason is that the aluminium silicate cushion may be not well attached to the surface of the specimen, as a result, a large amount of heat around the concrete was absorbed.

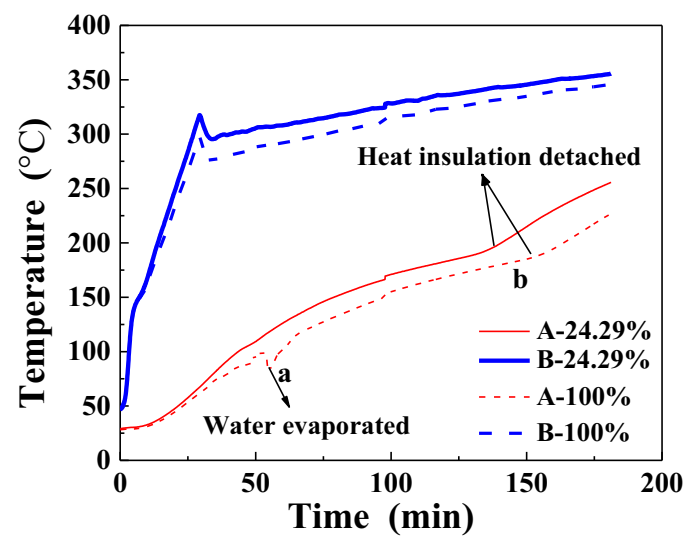

Fig4. Effect of saturation on concrete temperature conduction 
at $400{ }^{\circ} \mathrm{C}$ high temperature

Due to the evaporation of moisture, the surface temperature of the concrete with high saturation was relatively low. However, with the longer duration, the moisture is gradually reduced, the surface temperature of the two concrete specimens tends to be the same. The effect of moisture on temperature conduction is more pronounced in the interior of the concrete. The smaller the maximum temperature is set, the less heat is transferred in the same heating environment. For concrete with different saturation, the higher the saturation, the lower the internal temperature, Compared with Figs. 3 and 4 . The saturation of concrete has a significant effect on the heat transfer of concrete at high temperatures.

\section{Conclusion}

In this paper, heat transfer in concrete with different saturation degree at high temperatures was experimentally studied. From the results and discussions, the following conclusions can be reached:

For concrete with different saturations subjected to withstand high temperature, the higher saturation degree is, the lower temperature is at the concrete surface. More importantly, for the temperature inside of concrete, the temperature is even more lower in saturated concrete compared with the temperature of dried concrete at the same depth.

The water content has a significant influence on the temperature field of the concrete under high temperature. When the internal temperature of the concrete reaches $100^{\circ} \mathrm{C}$, the temperature difference of the concrete with and without water saturation is as high as $30{ }^{\circ} \mathrm{C}$. However, quantitative analysis of the difference still requires further investigation.

\section{Acknowledgements}

This work is supported by the Guangzhou City Industry-university-research Cooperation (Project No. 201604020056) and China Postdoctoral Science Foundation (Project No.2017M622633).

\section{References}

1. Xie, W., et al. (2007). "Discussion on bursting mechanism of high strength concrete at high temperature." New Building Materials.

2. Kalifa, P., et al. (2000). "Spalling and pore pressure in HPC at high temperatures." Cement \& Concrete Research 30(12): 1915-1927.
3. Wong, Y. L., et al. (2006). "Spalling of concrete cover of fiber-reinforced polymer reinforced concrete under thermal loads." Materials \& Structures 39(10): 991-999.

4. Peng, G. F., et al. (2006). "Explosive spalling and residual mechanical properties of fiber-toughened high-performance concrete subjected to high temperatures." Cement \& Concrete Research 36(4): 723-727.

5. Hertz, K. D. (2003). "Limits of spalling of fire-exposed concrete." Fire Safety Journal 38(2): 103-116.

6. Li, M., et al. (2004). "Mechanical properties of high-strength concrete after fire." Journal of the Chinese Ceramic Society 34(6): 1001-1005.

7. Qian-qian, Y., et al. (2015). "Effect of Moisture Content and Fiber on High-temperature Property of Tunnel Second Lining Concrete." Journal of Highway and Transportation Research and Development (English Edition) 9(3): 63-68.

8. Bian, S. H., et al. (2005). "Effects of Moisture Contents and Fibers on Properties of High Performance Concrete at High Temperatures." Journal of Building Materials 8(3): 321-327

9. Zhi-Sheng, X. U., et al. (2010). "Experimental research on influence for water content to the fire-resistant property of tunnel lining concrete." Journal of Railway Science \& Engineering.

10. Zhang, Y. and X. U. Zhi-Sheng (2010). "Discussion on effects of moisture contents in RC fire resistant experiments." Fire Safety Science.

11. Jiang, Y. C., et al. (2006)."Effects of reticular polypropylene fiber and PVA fiber on properties of High Performance Concrete at high temperatures." Ready-Mixed Concrete.

12. Partie. (1992). Eurocode 2: design of concrete structures. part 1. general rules and rules for buildings (together with united kingdom national application document).

13. Lie, T. T. (2010). "A procedure to calculate fire resistance of structural members." Fire \& Materials 8(1): 40-48. 